\title{
A comparative study of sperm-egg interactions in birds
}

\author{
T. R. Birkhead, B. C. Sheldon* and F. Fletcher \\ Department of Animal and Plant Sciences, PO Box 601, The University of Sheffield, \\ Sheffield S10 2UQ, UK
}

\begin{abstract}
A comparative study was made of the number of spermatozoa trapped on the outer perivitelline layer and the number of spermatozoa penetrating the inner perivitelline layer of the eggs of 27 species of bird. The total number of spermatozoa (trapped spermatozoa plus holes made by spermatozoa) varied between 29 and 164000 per egg among species and was significantly and positively correlated with size of the ovum. In most species, holes formed a 'halo' around the germinal disc area and the density of holes was much greater in this region than elsewhere, especially in passerine birds. In some species, a high proportion of holes occurred at some distance from the germinal disc. This seems to be an artefact due to the fact that some spermatozoa trapped in the outer perivitelline layer undergo proteolytic activity between fertilization and oviposition and create additional holes in the inner perivitelline layer both at and away from the germinal disc. Across all species and within most individual species, the number of trapped spermatozoa was positively correlated with the number of holes in the inner perivitelline layer. Decreases in the total number of spermatozoa on successive eggs of a clutch provided an index of the rate at which spermatozoa were used from the sperm storage tubules.
\end{abstract}

\section{Introduction}

In contrast to mammals in which the events leading up to and surrounding fertilization are known in some detail (Yanagimachi, 1988), the interaction between spermatozoa and ova in birds is poorly understood. The most detailed information available is for non-passerine birds such as domestic fowl (Gallus domesticus) and turkeys (Meleagris gallopavo) (Romanoff, 1960; Howarth, 1984; Perry, 1987), but very little is known about this aspect of reproduction in passerine birds. Unlike mammals, but in common with elasmobranchs, reptiles and some amphibians, birds exhibit physiological polyspermy where several spermatozoa typically penetrate the inner perivitelline layer of the ovum, only one of which fuses with the female pronucleus (Harper, 1904; Howarth, 1984; Perry, 1987). It has been suggested that polyspermy occurs in birds and other taxa that produce large, yolky (megalecithal) eggs because the germinal disc constitutes a relatively small target for the spermatozoa on the surface of the ovum (Bakst and Howarth, 1977). The observation that in birds a greater proportion of inseminated spermatozoa reach the site of fertilization within the female reproductive tract than in mammals is consistent with this idea (Birkhead et al., 1993a).

Fertilization in birds takes place in the infundibulum at the top of the female tract within about $15 \mathrm{~min}$ of the ovum being shed from the ovary (Howarth, 1984; Perry, 1987). Spermatozoa are present in the infundibulum throughout most of the female's fertile period, having been released from the sperm storage tubules located at the utero-vaginal junction. After

*Present address: Department of Zoology, Uppsala University, Villavagen 9 , S-752 36 Uppsala, Sweden.

Received 23 October 1993. release from the ovary, the ovum is covered by the inner perivitelline layer; as spermatozoa undergo the acrosome reaction, they leave relatively large holes as they penetrate this layer (Bakst and Howarth, 1977). Within minutes of fertilization, a second layer, called the outer perivitelline layer, is laid down on the ovum, trapping spermatozoa present in the infundibulum as it does so. The outer perivitelline layer is thought to act as a barrier to excessive polyspermy and to retain the integrity of the ovum already penetrated by some spermatozoa (Bakst and Howarth, 1977; Howarth, 1984). The first layers of albumen are laid down on the ovum within minutes of the egg being fertilized. The egg continues its development as it passes down the female tract, and oviposition occurs $24 \mathrm{~h}$ or more after fertilization (Johnson, 1986). The number of spermatozoa trapped on the outer perivitelline layer reflects the number of spermatozoa inseminated and present in the female tract (Wishart, 1987; Brillard and Bakst, 1990; Brillard and Antoine, 1991; Birkhead et al., 1993a). The number of holes in the inner perivitelline layer is also related to the numbers of spermatozoa on the outer layer in the zebra finch (Taeniopygia guttata; Birkhead et al., 1993a). The sum of the number of spermatozoa trapped on the outer perivitelline layer plus the number penetrating the inner perivitelline layer (as indicated by the number of holes), which is referred to in this article as the total number of spermatozoa, provides the best estimate of the overall numbers of spermatozoa reaching the ovum at the site of fertilization.

The aim of the present study was to examine the relationship between ovum size and the total number of spermatozoa for a range of passerine and non-passerine birds, and to determine the spatial distribution of spermatozoa and holes in the inner perivitelline layer. 


\section{Materials and Methods}

\section{Collection of eggs}

Freshly laid, unincubated eggs were obtained (under the appropriate licences) from a range of wild and captive bird species (Table 1). For some species entire clutches were obtained and the sequence in which they were laid was known. Since our sample sizes for individual species are sometimes small, the results should perhaps be considered preliminary, although the data are probably adequate to fulfil our main objective of identifying general patterns.

\section{Measurement of spermatozoa and holes in the inner perivitelline layer}

Eggs were opened with scissors and the yolk and albumen separated. The diameter of the yolk (i.e. the ovum) and the germinal disc were measured using vernier calipers (to the nearest $0.1 \mathrm{~mm}$ ). The perivitelline layers were removed as a single unit by cutting the ovum into two with scissors, but ensuring that the germinal disc was not damaged. For small birds, the entire membrane, in two halves, was mounted onto a glass slide for examination under a microscope. For larger birds, two pieces of perivitelline layer were mounted, one containing the germinal disc and the other from the other piece of tissue. A drop of the fluorescent Hoechst dye 33342 was placed on each piece of perivitelline layer to stain the nuclei of the spermatozoa (Wishart, 1987), and viewed at magnifications of $\times 25$ or $\times 40$. Holes in the inner perivitelline layer were viewed with dark field optics usually at a magnification of $\times 10$. The density of attached spermatozoa and holes in the vicinity of the germinal disc were measured by positioning the germinal disc centrally in the field of view and counting one or more fields (depending upon the magnification). The measurement of the germinal disc diameter made on the intact ovum (above) was used to determine its extent when viewed under the microscope. Detailed examination of slide preparations of the perivitelline layer showed that the 'halo' of holes in the germinal disc region, described by Bramwell and Howarth (1992), covered only $0.637 \pm 0.04 \mathrm{SE}$ of the germinal disc area measured on the intact ovum (based on five species). In calculating the density of spermatozoa and holes in this region the measured diameter was multiplied by this factor. It was not possible to correct for the size of area generally free of holes within the 'halo', so our density estimates should be considered an index rather than an absolute measurement. Densities are expressed $\mathrm{mm}^{2}$.

\section{Comparative analyses}

In comparative studies, individual species cannot be considered as independent observations because similarities between them can be due either to common ancestry or to convergent evolution (Harvey and Pagel, 1991). To control for phylogenetic effects statistically independent linear contrasts between taxa were calculated, as recommended by Harvey and Pagel (1991), to test whether a change in a dependent variable was associated with a change in one or more independent variables. Linear contrasts were derived from comparisons within taxa at each node of a phylogeny (using the phylogeny of Sibley and Alquist (1990)), a method that reduces the information to a number of statistically independent data points. Contrasts were standardized assuming that the time since divergence was directly proportional to the number of taxa. Linear regressions of contrasts in dependent variables versus contrasts in independent variables were forced through the origin as recommended by Harvey and Pagel (1991) and Purvis (1991). The slopes of regressions between contrasts, forced through the origin, are given for illustrative purposes only, since it is not appropriate to infer evolutionary relationships from such slopes (Harvey and Pagel, 1991). Details of the method used to calculate independent contrasts are given by Purvis (1991). As well as presenting relationships between contrasts, figures are also presented showing the uncorrected relationships for comparison. When features of the interaction between spermatozoa and eggs of passerine birds were compared with non-passerines, means for each family within this classification were used since this controls for the possibility of speciose families biasing relationships. However, since no formal methods exist for controlling for phylogeny when comparing means, statistical tests for such comparisons are not presented. All analyses were performed on log-transformed data and all means are presented $\pm \mathrm{SE}$.

\section{Results}

\section{Repeatability}

For those species for which eggs were obtained from more than one female, repeatability analyses (Lessells and Boag, 1987) confirmed that significant and consistent differences occurred between species in the total number of spermatozoa (i.e. the number of spermatozoa plus the number of holes) (repeatability $(r)=0.698, F_{5,10}=6.96, P<0.005$ ), numbers of spermatozoa $\left(r=0.856, F_{6,19}=21.03, P<0.0001\right)$ and number of holes $\left(r=0.535, F_{5,10}=3.96, P<0.05\right)$. In addition, within most species repeatabilities were not significant, indicating that most of the variation in the interaction between spermatozoa and eggs is accounted for by differences between species (see Table 1). We therefore feel justified in drawing conclusions on the relationships across species, despite having relatively small sample sizes for some species.

\section{Ovum size, germinal disc size and numbers of spermatozoa}

In an analysis of independent contrasts ovum (yolk) size was positively and significantly correlated with body mass across species $\left(F_{1,21}=61.00, P<0.0001\right)$. Germinal disc size was also positively and significantly correlated with ovum size $\left(F_{1,21}=10.09, P=0.0045\right)$, but not with body mass, although this relationship approached significance $\left(F_{1,21}=4.15\right.$, $P=0.055$ ). The slope of the relationship (in the raw data) between germinal disc size and ovum size $(\beta=0.496 \pm 0.076)$, was $<1$, indicating that larger ova had relatively small germinal discs.

The total number of spermatozoa per ovum varied markedly between species, from just 29 in the dunnock (Prunella 
Table 1. Number of eggs and clutches for bird species used in the present study

\begin{tabular}{|c|c|c|c|c|c|}
\hline \multirow[b]{2}{*}{ Species } & \multicolumn{2}{|c|}{ Number of clutches } & \multirow[b]{2}{*}{ Sequence ${ }^{a}$} & \multirow[b]{2}{*}{ Number of eggs } & \multirow{2}{*}{$\begin{array}{l}\text { Bred wild (W) } \\
\text { or in captivity }(\mathrm{C})\end{array}$} \\
\hline & Complete & Part & & & \\
\hline $\begin{array}{l}\text { 23. Greater rhea } \\
\text { (Rhea americana) }\end{array}$ & & 1 & 一 & 1 & C \\
\hline $\begin{array}{l}\text { 4. Domestic goose } \\
\text { (Anser anser) }\end{array}$ & & 1 & - & 1 & C \\
\hline $\begin{array}{r}\text { 5. Barnacle goose } \\
\text { (Branta leucopsis) }\end{array}$ & 1 & & $Y$ & 3 & C \\
\hline $\begin{array}{l}\text { 1. Wood duck } \\
\text { (Aix sponsa) }\end{array}$ & & 4 & $\mathrm{~N}$ & 4 & C \\
\hline $\begin{array}{l}\text { 3. Red-legged partridge } \\
\text { (Alectoris rufa) }\end{array}$ & & 1 & $\mathrm{~N}$ & 4 & C \\
\hline $\begin{array}{l}\text { 18. Grey partridge } \\
\text { (Perdix perdix) }\end{array}$ & & 2 & $Y$ & 12 & $\mathrm{C}$ \\
\hline $\begin{array}{l}\text { 7. Japanese quail } \\
\text { (Coturnix japonica) }\end{array}$ & & 15 & $\mathrm{~N}$ & 15 & C \\
\hline $\begin{array}{l}\text { 12. Domestic fowl } \\
\text { (Gallus domesticus) }\end{array}$ & 1 & & $\mathrm{~N}$ & 3 & C \\
\hline $\begin{array}{l}\text { 19. Common pheasant } \\
\text { (Phasianus colchicus) }\end{array}$ & & 6 & $\mathrm{~N}$ & 6 & C \\
\hline $\begin{array}{l}\text { 13. Guineafowl } \\
\text { (Numida meleagris) }\end{array}$ & & 5 & $\mathrm{~N}$ & 5 & C \\
\hline $\begin{array}{l}\text { 11. Moorhen } \\
\text { (Gallinula chloropus) }\end{array}$ & 1 & & Y & 7 & W \\
\hline $\begin{array}{l}\text { 2. Razorbill } \\
\text { (Alca torda) }\end{array}$ & 1 & & - & 1 & W \\
\hline $\begin{array}{l}\text { 17. Common guillemot } \\
\text { (Uria aalge) }\end{array}$ & 1 & & - & $I$ & W \\
\hline $\begin{array}{l}\text { 10. Atlantic puffin } \\
\text { (Fratercula arctica) }\end{array}$ & 1 & & - & 1 & W \\
\hline $\begin{array}{l}\text { 6. Wood pigeon } \\
\text { (Columba palumbus) }\end{array}$ & 1 & 1 & Y & 3 & W \\
\hline $\begin{array}{l}\text { 21. Dunnock } \\
\text { (Prunella modularis) }\end{array}$ & 2 & & $Y$ & 8 & W \\
\hline $\begin{array}{l}\text { 9. Robin } \\
\text { (Erithacus rubecula) }\end{array}$ & 1 & & $Y$ & 5 & W \\
\hline $\begin{array}{l}\text { 26. European blackbird } \\
\text { (Turdus merula) }\end{array}$ & 3 & & $Y$ & 13 & W \\
\hline $\begin{array}{l}\text { 14. Bearded tit } \\
\text { (Panurus biamicus) }\end{array}$ & & 1 & $\mathrm{~N}$ & 2 & W \\
\hline $\begin{array}{l}\text { 22. Penduline tit } \\
\text { (Remiz pendulinus) }\end{array}$ & & 3 & $\mathrm{~N}$ & 3 & W \\
\hline $\begin{array}{l}\text { 15. Blue tit } \\
\text { (Parus caeruleus) }\end{array}$ & 2 & & $\mathrm{Y}$ & 20 & W \\
\hline $\begin{array}{l}\text { 8. Reed bunting } \\
\text { (Emberiza schoeniclus) }\end{array}$ & & 1 & $\mathrm{~N}$ & 1 & W \\
\hline $\begin{array}{l}\text { 25. Zebra finch } \\
\text { (Taeniopygia guttata) }\end{array}$ & 10 & & $Y$ & 43 & C \\
\hline $\begin{array}{l}\text { 16. House sparrow } \\
\text { (Passer domesticus) }\end{array}$ & & 1 & $\mathrm{~N}$ & 4 & W \\
\hline $\begin{array}{l}\text { 24. European starling } \\
\text { (Sturnus vulgaris) }\end{array}$ & & 3 & $\mathrm{~N}$ & 5 & W \\
\hline $\begin{array}{l}\text { 20. Magpie } \\
\text { (Pica pica) }\end{array}$ & 1 & $I$ & $Y$ & 10 & W \\
\hline
\end{tabular}

Taxonomic list follows Howard and Moore (1991) and numbers are those used in figures. Note that all species bred in captivity were allowed to mate freely (including domestic fowl, which were free-range bantams). Repeatability of the numbers of spermatozoa and holes between species was high, but between females within species only two of 19 calculated values were significant.

${ }^{a} \mathrm{Y}$ : data about the sequence in which a clutch or part of a clutch was laid was obtained; N: no sequence data. 

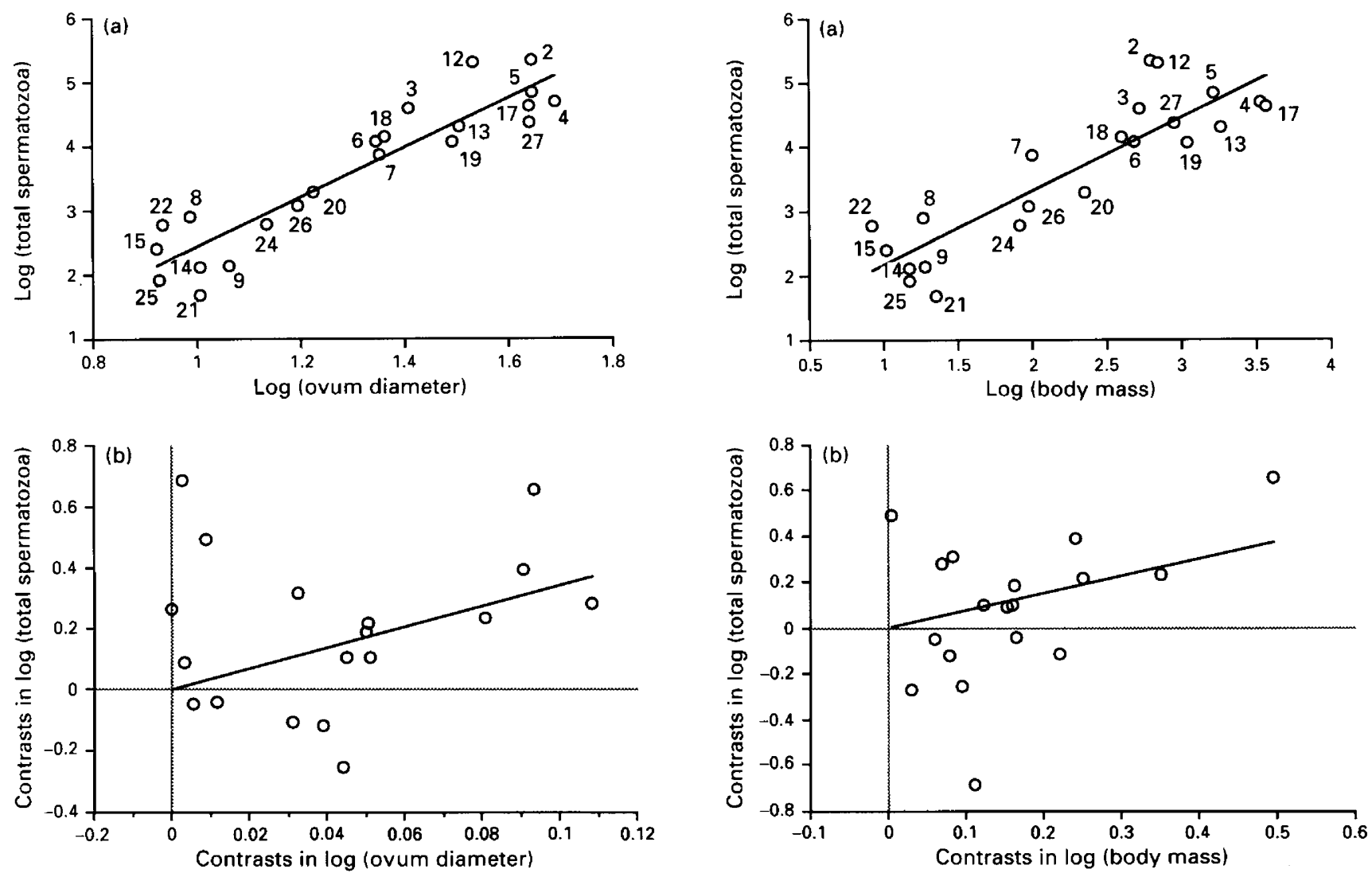

Fig. 1. (a) Relationship between log (ovum size) and log (total number of spermatozoa (i.e. number of spermatozoa plus the number of holes made by spermatozoa in the inner perivitelline layer)). Points refer to individual species of bird identified by numbers in Table 1 . (b) Relationship between contrasts in log (ovum) size and log (total spermatozoa): $\beta=3.587$ (SE: 1.297 ), $F_{1,17}=7.655, P=0.013$.

modularis) to 164000 in the domestic fowl (Gallus domesticus) and was positively and significantly correlated with ovum size (Fig. 1a; $F_{1.17}=8.40, P=0.010$ ). The slope of this relationship in the raw data $(\beta=3.221 \pm 0.49)$ was $>1$, indicating that disproportionately large numbers of spermatozoa reached larger ova. The relationship between contrasts in total number of spermatozoa and body mass was also positive (Fig. 2a; $F_{1,17}=4.827, P=0.042$ ). These effects were not evident when controlling for the other variable (total spermatozoa versus ovum size, controlling for body mass $\left(F_{1,16}=2.63, P=0.12\right)$, total number of spermatozoa versus body mass, controlling for ovum size $\left.\left(F_{1,16}=0.01, P=0.92\right)\right)$, presumably because ovum size and body mass were highly correlated. However, multiple regression showed that body mass and ovum size together did explain a significant amount of the variance in the total number of spermatozoa $\left(F_{2,16}=3.961, P=0.040 ; r^{2}=0.331\right)$ (see Table 2).

The relationships between the number of spermatozoa attached to the perivitelline layer and the numbers of holes in the perivitelline layer were also considered separately with ovum size and body size. The number of spermatozoa attached to the perivitelline layer was positively and significantly correlated with both ovum size and body mass (Table 2). The

Fig. 2. (a) Relationship between log (body mass) and log (total spermatozoa (i.e. number of trapped spermatozoa plus the number of holes made by spermatozoa in the inner perivitelline layer)). Points refer to individual species of bird identified by numbers in Table 1 . (b) Relationship between contrasts in log (body mass) and log (total spermatozoa): $\beta=0.739$ (SE: 0.377 ), $F_{1,17}=3.852, P=0.066$.

relationships with contrasts in the number of holes in the perivitelline layer were not significant (Table 2), although all were tending in the same direction as those between total number of spermatozoa and ovum size and body mass. Overall, the results indicate that ovum size is the best predictor of the total numbers of spermatozoa, although body mass also has an effect.

There was a positive relationship between contrasts in germinal disc size and the number of holes in the germinal disc, although this was not significant $\left(F_{1,17}=3.227, P=0.09\right)$. However, after controlling for ovum size, any suggestion of a relationship between germinal disc size and the number of holes was not seen $\left(F_{1,16}=1.351, P=0.26\right)$.

\section{Distribution of holes and spermatozoa on the perivitelline layers}

In most species of passerine and non-passerine birds the holes tended to form a halo around the germinal disc region, with few or no holes at the centre of the germinal disc (Fig. 3). Across all species, the density of holes $\left(\mathrm{mm}^{-2}\right)$ was almost ten times higher over the germinal disc area $(27.23 \pm 5.32 ; n=22$ species) than elsewhere on the ovum $(2.96 \pm 1.36)$. This effect was particularly pronounced in passerines: the ratio of holes 
Table 2. Relationship between contrasts in total spermatozoa ${ }^{a}$, numbers of trapped spermatozoa and number of holes in the inner perivitelline layer, and ovum size and body mass of different bird species

\begin{tabular}{|c|c|c|c|c|c|}
\hline Compare variables & $n$ & $r^{2}$ & $F$ & $P$ & Slope (SE) \\
\hline \multicolumn{6}{|l|}{ Total spermatozoa } \\
\hline Ovum size & 18 & 0.331 & 8.402 & $0.010^{*}$ & $3.438(1.186)$ \\
\hline Ovum size and body mass ${ }^{\mathrm{b}}$ & 18 & - & 2.632 & 0.102 & $3.620(2.232)$ \\
\hline Body mass & 18 & 0.221 & 4.827 & $0.042 *$ & $0.757(0.345)$ \\
\hline Body mass and ovum size ${ }^{\mathrm{b}}$ & 18 & - & 0.009 & 0.924 & $-0.059(0.601)$ \\
\hline Overall model ${ }^{c}$ & 18 & 0.331 & 3.961 & $0.040^{*}$ & $-\quad-$ \\
\hline \multicolumn{6}{|l|}{ Numbers of spermatozoa } \\
\hline Ovum size & 22 & 0.222 & 6.002 & $0.023^{*}$ & $3.393(1.385)$ \\
\hline Ovum size and body mass ${ }^{\mathrm{b}}$ & 22 & - & 0.276 & 0.605 & $1.449(2.759)$ \\
\hline Body mass & 22 & 0.256 & 7.209 & $0.014^{*}$ & $1.007(0.375)$ \\
\hline Body mass and ovum size ${ }^{\mathrm{b}}$ & 22 & - & 0.667 & 0.424 & $0.629(0.770)$ \\
\hline Overall model ${ }^{c}$ & 22 & 0.247 & 3.287 & 0.058 & $-\quad-$ \\
\hline \multicolumn{6}{|l|}{ Numbers of holes } \\
\hline Ovum size & 18 & 0.172 & 3.538 & 0.077 & $2.982(1.585)$ \\
\hline Ovum size and body mass ${ }^{b}$ & 18 & - & 2.550 & 0.130 & $4.694(2.939)$ \\
\hline Body mass & 18 & 0.069 & 1.251 & 0.279 & $0.507(0.453)$ \\
\hline Body mass and ovum size ${ }^{b}$ & 18 & - & 0.485 & 0.496 & $-0.551(0.792)$ \\
\hline Overall model ${ }^{\mathrm{c}}$ & 18 & 0.197 & 1.958 & 0.174 & $-\quad-$ \\
\hline
\end{tabular}

\footnotetext{
${ }^{a}$ Total spermatozoa: number of trapped spermatozoa plus number of holes in the inner perivitelline layer.

${ }^{b}$ The first variable controls for the effect of the second variable.

'Multiple regression model using both variables.

${ }^{*} P<0.05$.

$n$ : sample size; $r^{2}$ : proportion of the variance explained by the relationship; $F: F$ statistic; $P$ : probability.
}

over the germinal disc area to the ratio of holes away from this region in passerines was much higher $(273.43 \pm 77.19 ; n=7$ families) than that for non-passerines $(40.01 \pm 22.69 ; n=5$ families).

Across all species the density of spermatozoa also tended to be higher over the germinal disc area (13.90 $\pm 5.00 ; n=25$ species) than it was elsewhere on the perivitelline membrane $(5.57 \pm 2.12)$, although the difference was much less pronounced than that for holes (above). The ratio of spermatozoa over the germinal disc area to the spermatozoa away from this area was lower in passerines ( $9.65 \pm 0.797 ; n=7$ families) than in non-passerines (17.06 $\pm 11.89 ; n=7$ families).

It is difficult to explain why spermatozoa should penetrate the inner perivitelline layer away from the germinal disc, since the likelihood of these spermatozoa reaching the female pronucleus is extremely small. The idea that holes in the inner perivitelline layer away from the germinal disc are an artefact was therefore tested. In several species nuclei of spermatozoa were visible within holes, and in some passerines, entire spermatozoa were visible with their head inside a hole. This was not examined systematically, but in three of four species examined holes at the germinal disc were less likely to contain spermatozoa than were those away from the germinal disc. The percentage of holes with spermatozoa visible away from the germinal disc and at the germinal disc, respectively, and probabilities derived from chi-squared tests are as follows: blackbird: 3 eggs; (1) $39 \%, 3 \%(P<0.02),(2) 33 \%, 13 \%$ (NS), (3) $0 \%, 50 \%(P<0.001)$; blue tit: $1 \mathrm{egg} ; 80 \%, 12 \%(P<0.02)$; wood pigeon: 1 egg; $36 \%, 7 \%$ ( $P<0.03)$; magpie: 3 eggs; (1) $3 \%, \quad 0 \%$ (NS), (2) $0 \%, 9 \%$ (NS), (3) $0 \%, 3 \%$ (NS). The observations that some holes contained spermatozoon nuclei and that holes at the germinal disc were in general less likely to contain spermatozoa are consistent with the idea that following fertilization, some spermatozoa trapped in the outer perivitelline layer undergo proteolytic activity and create a hole in the inner perivitelline layer. In other words, it is possible that at the time of fertilization the majority of spermatozoa that penetrate the inner perivitelline layer do so at the germinal disc, but that subsequently other spermatozoa also make holes in this layer. This needs to be verified experimentally.

\section{Relationship between numbers of spermatozoa and numbers of holes}

Across species, when controlling for phylogeny, there was a significant and positive correlation between the number of spermatozoa on, and the number of holes in, the perivitelline layers $\left(F_{1,17}=19.60, P<0.0004 ;\right.$ Fig. 4$)$. This relationship was also examined for ten separate species. Analyses were performed either on eggs laid by the same female (i.e. eggs comprising a clutch) or on eggs each laid by a different female. However, because the number of eggs laid by a single female is small it is unlikely that individual correlations would be significant. The sign of the correlation coefficients was therefore used to assess whether there was any overall effect. The number of comparisons was 14 (because more than one clutch was available for some species: see Table 1 ) and of these 12 were positive (range: -0.478 to 0.991 ). To avoid pseudoreplication, the mean correlation coefficient was calculated for those species with more than one clutch: nine of the ten species 

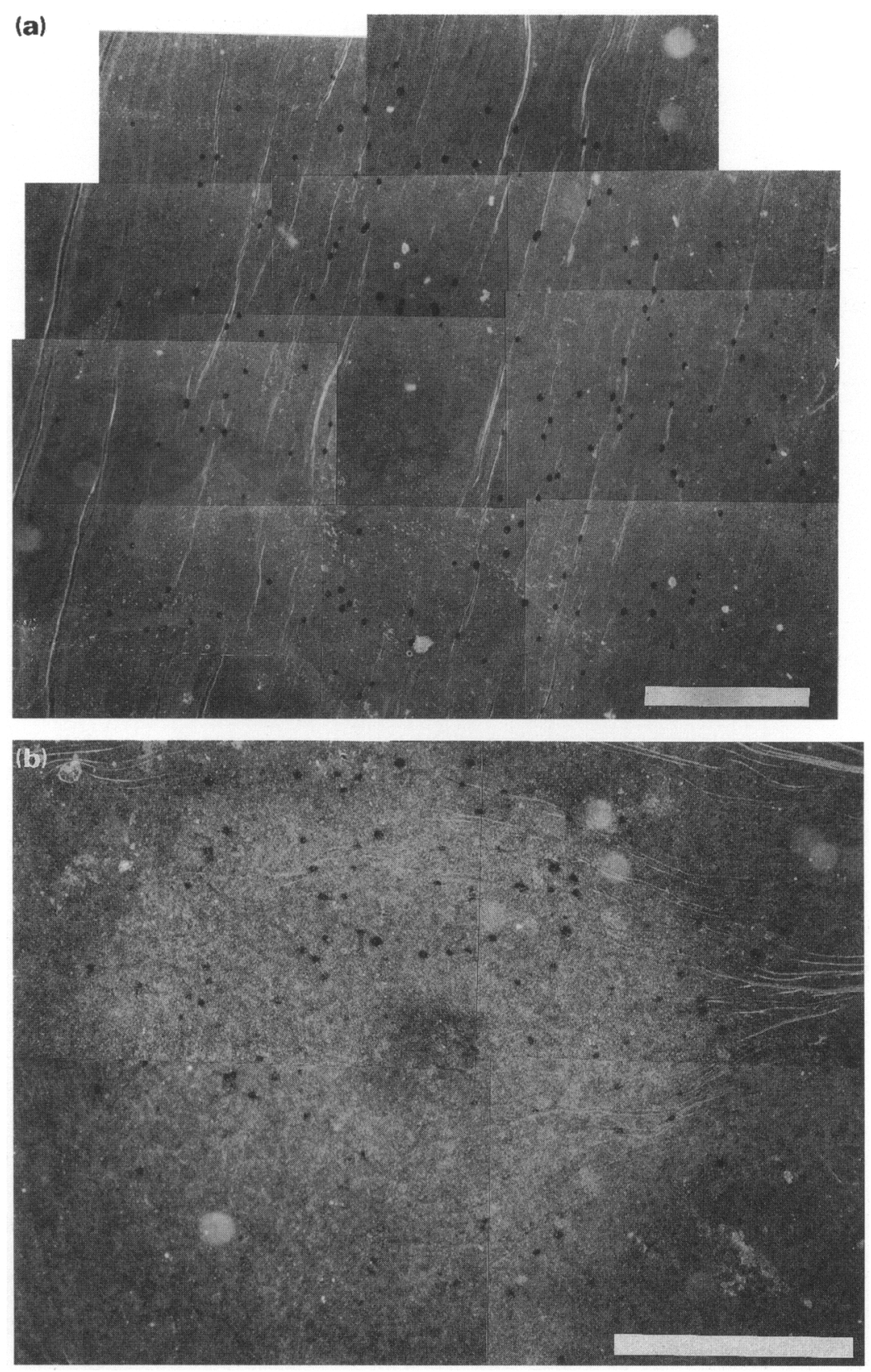

Fig. 3. Photographic montages of the germinal disc area of (a) grey partridge and (b) blue tit, showing holes in the perivitelline membrane. (Scale bars represent $0.5 \mathrm{~mm}$.)

showed positive correlations. The strength of the correlations varied both between females within species and between species, but our sample sizes are too small to draw any firm conclusions regarding interspecific differences.

\section{Total number of spermatozoa on successive eggs of a dutch}

Wishart (1987) showed that the numbers of spermatozoa on the perivitelline layers of successive domestic fowl eggs following a single insemination showed an exponential decline, reflecting the constant rate at which spermatozoa are lost from the sperm storage tubules (see also Brillard and Antoine, 1990;
Birkhead et al., 1993a). Our data show variable numbers of total spermatozoa through the laying sequence (Fig. 5), which presumably reflects the fact that in most of these species some inseminations occurred during the egg-laying period (Birkhead and Moller, 1993). Increases in the numbers of total spermatozoa on successive eggs must reflect inseminations and decreases may provide an estimate of the rate at which spermatozoa are lost from the sperm storage tubules. Information on decreases in $\log _{e}$ (total spermatozoa) on successive eggs are potentially useful because they may provide an indirect method for estimating the duration of sperm storage and the fertile period, which is currently unknown for wild 
(a)

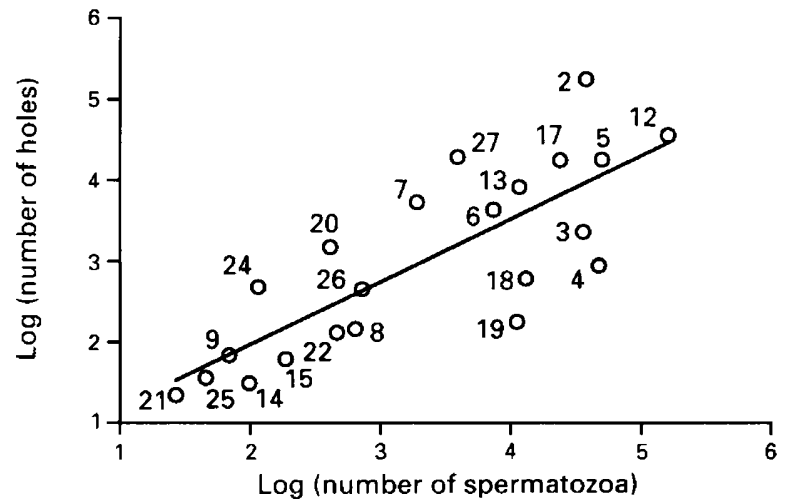

(b)

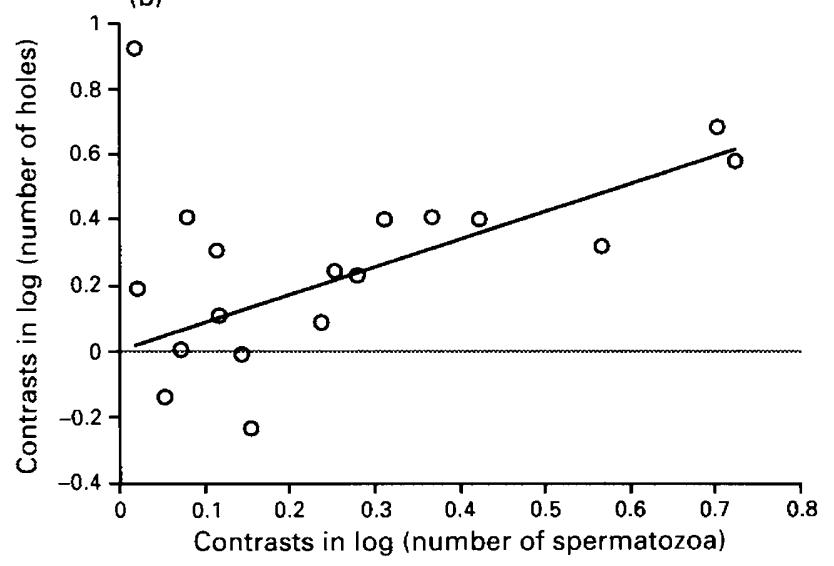

Fig. 4. (a) Relationship between log (number of spermatozoa) and log (number of holes). Points refer to individual species identified by numbers in Table 1. (b) Relationship between contrasts in log (number of spermatozoa) and $\log$ (number of holes): $\beta=0.875 \pm 0.183$, $F_{1,17}=22.80, P<0.001$.

birds (Birkhead and Fletcher, 1993). Estimates of the instantaneous loss rate of $\log _{e}$ (spermatozoa) $\mathrm{h}^{-1}$ for five wild bird species (Table 3) from Fig. 5 show that these are similar to, or higher than, those derived empirically for species in captivity (see footnote for Table 3). To check the validity of this method for estimating the instantaneous rate of sperm loss, we compared the empirically derived estimate for the zebra finch (0.026 $\log _{e}$ (spermatozoa) $h^{-1} \pm 0.007$; Birkhead et al., 1993a) with a second estimate made using the technique used on wild birds. This gave a similar value $\left(0.032 \log _{e}\right.$ (spermatozoa) $\mathrm{h}^{-1} \pm 0.005$ ) that did not differ significantly from the original estimate ( $t=0.697,20$ d.f., not significant), suggesting that the method we used on wild birds provides a reasonable estimate. The results for the passerines (range: 0.02-0.03) are similar to that for the zebra finch (0.026), indicating that the duration of sperm storage in passerine birds may also be similar to that species (median duration of 10 days; Birkhead et al., 1989).

\section{Size of holes in the inner perivitelline layer}

The size of holes differed significantly between species both for holes in the germinal disc (repeatability $=0.68$, $\left.F_{8,21}=7.737, P<0.001\right)$ and holes away from the germinal disc (a) Barnacle goose

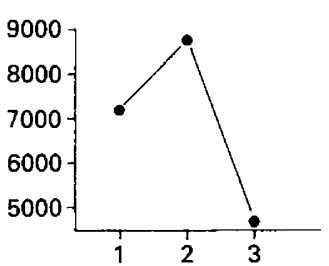

(b) Moorhen

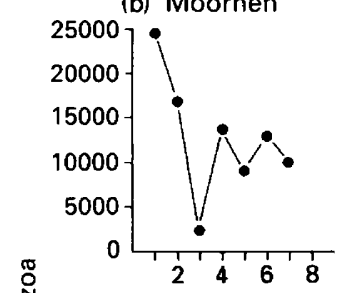

(c) Dunnock

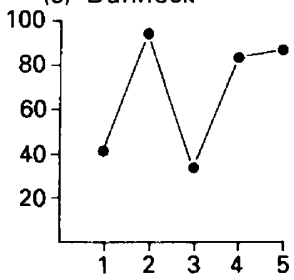

(d) Robin

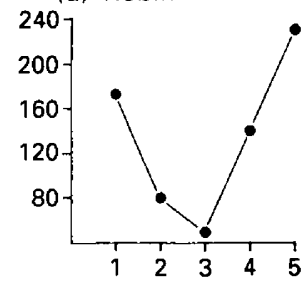

(e) Blackbird 1

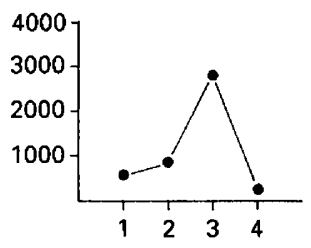

Egg number

(j) Magpie

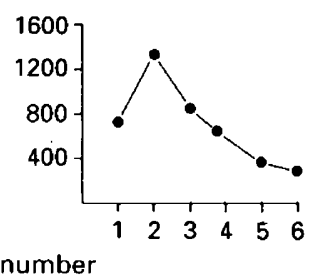

Fig. 5. Total number of spermatozoa (i.e. the number of trapped spermatozoa plus the number of holes made by spermatozoa in the inner perivitelline layer) on successive eggs within a clutch for seven species of bird. In all cases the number of spermatozoa refers to the total number of spermatozoa (spermatozoa plus holes), except for the moorhen (b), where the numbers are of spermatozoa only, because no holes were visible (see also Table 3 ).

(repeatability $=0.496, F_{0,12}=3.605, P=0.028$ ). The diameter of holes was relatively large compared with the size of spermatozoa, and varied from $10.44 \mu \mathrm{m}$ to $30.24 \mu \mathrm{m}$ between families. There was no obvious difference between passerines and non-passerines in hole diameter either in the germinal disc region $(17.20 \mu \mathrm{m} \pm 0.982$ for passerines versus $20.57 \pm 1.763$ for non-passerines; all birds, 18.579 \pm 0.97 ) or away from the germinal disc region ( $16.52 \pm 1.30$ for passerines versus $21.71 \pm 2.385$ for non-passerines; all birds, $18.709 \pm 1.356$ ). 
Table 3. Estimates of the instantaneous loss rate of $\log _{e}$ (spermatozoa) $\mathrm{h}^{-1}$ from the sperm storage tubules in wild birds derived from changes in the numbers of spermatozoa on the perivitelline membranes of successive eggs ${ }^{a}$

\begin{tabular}{lcc}
\hline Species & $\begin{array}{l}\text { Instantaneous loss rate } \\
\log _{e} \text { spermatozoa } \mathrm{h}^{-1}\end{array}$ & $\mathrm{SE}$ \\
\hline Moorhen & 0.048 & 0.018 \\
Blackbird & 0.026 & 0.001 \\
Magpie & 0.020 & 0.003 \\
Robin & 0.026 & 0.002 \\
Blue tit & 0.030 & 0.005 \\
\hline
\end{tabular}

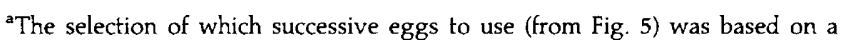
minimum of three successive eggs showing a decline in the total number of spermatozoa (i.e. spermatozoa plus holes, except in the case of the moorhen where only the number of spermatozoa was used because no holes were visible). The eggs used are as follows (see Fig. 5): Moorhen: 1-3, Blackbird 2: 3-5, Robin: 1-3, Blue tit 1 : $1-3$ and Blue tit 2: 1-4 inclusive.

The estimates in this table can be compared with those derived empirically for birds in captivity: zebra finch, $0.026 \pm 0.007$; Japanese quail, $0.015 \pm 0.002$; domestic fowl, $0.013 \pm 0.001$; and turkey $0.003 \pm 0.0003$ (see Birkhead et al., 1993).

${ }^{b}$ The blue tit estimate is the mean from two clutches $(0.041 \pm 0.004$ and $0.02 \pm 0.007$ ).

There was no relationship between contrasts in $\log$ (hole size at germinal disc) and (1) $\log$ (ovum size) $\left(F_{1,18}=0.372\right.$, $P=0.55)$, (2) $\log$ (germinal disc size) $\left(F_{118}=1.194, P=0.29\right)$, and (3) $\log$ (body mass) $\left(F_{1,18}=0.078, P=0.78\right)$. There was no relationship between log (hole size at the germinal disc), and either ovum or germinal disc size controlling for the other variable (residual ovum: $F_{1,17}=1.811, P=0.20$; residual germinal disc: $F_{1,17}=2.650, P=0.12$; combined model: $F_{2,17}=1.529$, $P=0.25$ ). The equivalent relationships involving log (hole size away from the germinal disc region) were also not significant.

\section{Discussion}

The number of spermatozoa reaching the ova was positively correlated with ovum size across the bird species studied. This result is consistent with the idea that larger ova require more spermatozoa to ensure fertilization (Rothschild, 1956; Bramwell and Howarth, 1992). Moreover, since larger ova possess relatively smaller germinal discs these represent relatively smaller targets on larger eggs. This in turn could explain why the slope of the relationship between the total spermatozoa and ovum size was greater than 1: a disproportionately large number of spermatozoa are required to be inseminated for them to be at the same density on the germinal disc in larger species.

Most spermatozoa penetrated the inner perivitelline layer mainly at the germinal disc (see also Bramwell and Howarth, 1992), and it is possible that this region specifically attracts spermatozoa (Howarth and Digby, 1973). However, this hypothesis also predicts a positive relationship between the size of the germinal disc and the number of holes it contains, but we did not find this effect. For unknown reasons the clustering of holes at the germinal disc was particularly pronounced in passerines.
The total number of spermatozoa on the perivitelline layers of ova will be a function of several factors in addition to the size of the ovum. These include the number of spermatozoa per ejaculate, mating and insemination frequency, and the extent to which females 'select' spermatozoa from within ejaculates. In birds, ejaculate size increases disproportionately with body mass (Møller, 1988). Mating frequency varies markedly across species, mainly in relation to the intensity of sperm competition: species experiencing more intense sperm competition mate more frequently (Birkhead and Moller, 1992). It was once thought that females were passive receptacles for spermatozoa, but there is increasing evidence that females might have some control over the paternity of their offspring through the passive or active selection of inseminated spermatozoa (Madsen et al, 1992; Lifjeld and Robertson, 1992; Birkhead ef al., 1993b). The proportion of inseminated spermatozoa that reach the sperm storage tubules varies between species (Birkhead et al., 1993a), and this will also affect the numbers that appear on ova. The hostility of the female reproductive tract towards spermatozoa is well known (Bedford, 1970; Birkhead et al., 1993b) and the female tract contains a succession of filters ensuring that only a tiny proportion of the spermatozoa reach the site of fertilization (Bedford, 1970; Roldan et al., 1992). The function of such selection of spermatozoa remains controversial (see Birkhead et al., 1993b). In birds, the main point at which selection occurs is in the vagina before spermatozoa enter the sperm storage tubules (Steele and Wishart, 1992; Birkhead et al., 1993a). However, our observation that the ratio of trapped to penetrating spermatozoa varies between species and that the thickness of the perivitelline layers varies between species suggests that this might be another opportunity for the female to select spermatozoa for fertilization. To date there have been no attempts to measure the thickness of the inner perivitelline layer in different bird species, although this has been done for the domestic fowl (Bellairs et al., 1963).

The authors are grateful to the following who provided or helped us find eggs: T. D. Croft, Chatsworth Game Farm, D. Follett, B. J. Hatchwell, H. Hoi, N. Hart (Marwell Zoological Park), A. P. Møller, Q. Spratt, The Wildfowl Trust, T. D. Williams, S. A. Wilson and J. Wright. They also thank A. P. Moller, H. Moore, G. Wishart and two anonymous referees for helpful comments on the manuscript. This work was supported by a grant from SERC to T. R. Birkhead.

\section{References}

Bakst MR and Howarth B, Jr (1977) Hydrolysis of the hen's perivitelline layer by cock sperm in vitro Biology of Reproduction 17 370-379

Bedford, JM (1970) The saga of mammalian sperm from ejaculation to syngamy. In Mammalian Reproduction, pp 124-182 Eds H Gibian and EJ Plotz. Springer-Verlag, Berlin

Bellairs R, Harkness ML and Harkness RD (1963) The vitelline membrane of the hen's egg: a chemical and ultrastructural study Journal of Ultrastructure Research 8 339-359

Birkhead TR and Fletcher F (1993) Storage and release of sperm from the sperm storage tubules in Japanese quail Coturnix japonica Ibis 136 101-105

Birkhead TR and Meller AP (1992) Sperm Competition in Birds: Evolutionary Causes and Consequences. Academic press, London

Birkhead TR and Moller AP (1993) Why do male birds stop copulating while their partners are still fertile? Animal Behaviour 45 105-118

Birkhead TR, Hunter FM and Pellatt EJ (1989) Sperm competition in the zebra finch Taeniopygia guttata Animal Behaviour 38 935-950 
Birkhead TR, Pellatt EJ and Fletcher F (1993a) Selection and utilization of spermatozoa in the reproductive tract of the female zebra finch Taeniopygia guttata Journal of Reproduction and Fertility 99 593-600

Birkhead TR, Maller AP and Sutherland WJ (1993b) Why do females make it so difficult for males to fertilize their eggs? Journal of Theoretical Biology 161 $51-60$

Bramwell RK and Howarth B (1992) Preferential attachment of cock spermatozoa to the periviteiline layer directly over the germinal disc of the hen's ovum Biology of Reproduction 47 1113-1117

Brillard JP and Antoine H (1990) Storage of sperm in the uterovaginal junction and its incidence on the numbers of spermatozoa present in the perivitelline layer of hens' eggs British Poultry Science 31 635-644

Brillard JP and Bakst MR (1990) Quantification of spermatozoa in the spermstorage tubules of turkey hens and its relation to sperm numbers in the perivitelline layer of eggs Biology of Reproduction 43 271-275

Harper EH (1904) The fertilization and early development of the pigeon's egg American Journal of Anatomy 3 349-386

Harvey PH and Pagel MD (1991) The Comparative Method in Evolutionary Biology Oxford University Press, Oxford

Howard, R and Moore A (1991) A Complete Checklist of the Birds of the World Academic Press, London

Howarth B Jr (1984) Maturation of spermatozoa and mechanism of fertilization. In Reproductive Biology of Poultry, pp 161-174 Eds EJ Cunningham, PE Lake and D Hewitt. Longman, Harlow

Howarth B Jr and Digby ST (1973) Evidence for the penetration of the vitelline membrane of the hen's ovum by a trypsin-like acrosomal enzyme Journal of Reproduction and Fertility 33 123-125

Johnson AL (1986) Reproduction in the female. In Avian Physiology, pp 403-431 Ed. PD Sturkie. Springer-Verlag, New York
Lessells CM and Boag P (1987) Unrepeatable repeatabilities: a common mistake Auk 104 116-121

Lifjeld JT and Robertson RJ (1992) Female control of extra-pair fertilization in tree swallows Behavioral Ecology and Sociobiology 31 89--96

Madsen T, Shine R, Loman JR and Hakansson T (1992) Why do female adders copulate so frequently? Nature 355 440-44I

Moller AP (1988) Testis size, ejaculate quality, and sperm competition in birds Biological Journal of the Linnean Society 33 273-383

Perry MM (1987) Nuclear events from fertilisation to the early cleavage stages in the domestic fowl (Gallus domesticus) Journal of Anatomy $15099-109$

Purvis A (1991) Comparative Analysis by Independent Contrasts (C.A.I.C.): a Statistical Package for the Apple Macintosh. Version 1.2 Department of Zoology, Oxford University, Oxford

Roldan ESR, Gomendio M and Vitullo AD (1992) The evolution of eutherian spermatozoa and underlying selective forces: female selection and sperm competition Biological Reviews 67 551-593

Romanoff AL (1960) The Avian Embryo: Structural and Functional Development Macmillan, New York

Rothschild L (1956) Fertilization Methuen, London

Sibley CG and Alquist JE (1990) Phylogeny and Classification of Birds: a Study in Molecular Evolution Yale University Press, London and New Haven

Steele MG and Wishart GJ (1992) Characterisation of a mechanism impeding sperm transport through the vagina of the chicken. In Proceedings of the 12th International Congress on Animal Reproduction (Vol 3), pp 474-476 The Hague

Wishart GJ (1987) Regulation of the length of the fertile period in the domestic fowl by numbers of oviductal spermatozoa as reflected by those trapped in laid eggs Journal of Reproduction and Fertility 80 493-498

Yanagimachi R (1988) Mammalian fertilization. In The Physiology of Reproduction, pp 135-185 Eds E Knobil and J Neill. Raven Press, New York 